\title{
Maturidade em Gestão do Conhecimento: Pesquisa sobre utilização da Inteligência Competitiva em óticas localizadas no Centro de Cuiabá-MT
}

\author{
Max Nunes Murtinho ${ }^{1}$; José Jaconias da Silva²; André Torres Urdan ${ }^{3}$.
}

\begin{abstract}
Resumo
A Inteligência Competitiva se impõe como uma excelente ferramenta estratégica para a sobrevivência das organizações em cenário de concorrência tão agressiva. Tal contingência nos leva a pressupor que, as organizações que sobrevivem a mais tempo no mercado, mesmo que informalmente, devem possuir algum tipo de inteligência que os leva a competir em alto nível, haja vista a complexidade do cenário em que estão situados, pois de outra maneira, dificilmente conseguiriam se estabelecer por tanto tempo. Tendo isso em vista, o objetivo da pesquisa é caracterizar o nível de maturidade no uso de Inteligência Competitiva das óticas localizadas na rua das óticas, Centro de Cuiabá-MT. Quanto aos procedimentos metodológicos trata-se de um estudo multi-caso onde é aplicado o Modelo de Maturidade em Inteligência Competitiva proposto por Rodrigues e Riccardi (2007). O resultado identificou a proeminência do nível 1 na Maturidade em Inteligência Competitiva das óticas pesquisadas, sendo classificadas como informais.
\end{abstract}

Palavras-chave: Inteligência Competitiva; Modelo de Maturidade; óticas.

\footnotetext{
${ }^{1}$ Doutorando do Programa de Pós-Graduação em Administração da UNINOVE; Mestre em Agronegócio e Desenvolvimento Regional pela Faculdade de Economia da UFMT (2009) e Graduado em Economia pela UFMT (2006). Atua como Professor na Faculdade de Economia da UFMT. E-mail: maxmurtinho@ hotmail.com

${ }^{2}$ Doutorando do Curso de Administração da Universidade Nove de Julho (UNINOVE); Mestre em Engenharia de Produção pela Universidade Federal de São Carlos (2011). Especialista em Economia Solidária pela Universidade do Estado de Mato Grosso. Graduado em Agronomia pela Universidade do Estado de Mato Grosso (2005). Graduação em Administração pela Universidade do Estado de Mato Grosso (2002). Tem Experiencia em ministrar aulas de logística e operações e também experiência na área de Agronomia, com ênfase em Agricultura Familiar e Extensão Rural. Trabalhou como Professor na UNIC Universidade de Cuiabá de 2007 a 2013 e na UNEMAT - Universidade do Estado de Mato Grosso de 2009 a 2013. Ingressou como Professor Assistente do Curso de Administração da UFMT. E-mail: josejaconias@gmail.com

${ }^{3}$ professor do Mestrado Acadêmico e Doutorado em Administração da Universidade Nove de Julho. Foi professor titular do Departamento de Mercadologia da FGV-EAESP (1999 a 2014), professor adjunto da UFMG e professor doutor da FEA-USP. Doutor em Administração pela FEA-USP (1993) e Mestre em Administração de Empresas pela FGV-EAESP (1992). É graduado em Engenharia Civil (1984) e Administração (1987) pela UFMG, em Ciências Contábeis pela PUC-MG (1986). E-mail: andre,urdan@gmail.com
} 


\title{
Maturity in Knowledge Management: Research on the use of Competitive Intelligence in opticians located in the Center of Cuiabá-MT
}

\begin{abstract}
Competitive Intelligence stands as an excellent strategic strategy for a survival of organizations in a scenario of such aggressive competition. This contingency leads us to assume that, as organizations that survive longer without market, even informally, it must have some kind of intelligence that leads to compete at a high level, given the complexity of the scenario in which they are located, way, could hardly be established for so long. The objective of the research is a mathematical model without the use of Competitive Intelligence of the optics located in the optical street, Center of Cuiabá-MT. As for a process as a multi-case method where the Matrix Model in Competitive Intelligence proposed by Rodrigues and Riccardi (2007) is applied. The result identifies a prominence of level 1 of HF Maturity and can be classified as informal.
\end{abstract}

Keywords: Competitive Intelligence; Maturity Model; optics.

Classificação JEL: M19.

\section{Introdução}

Um fenômeno inegável no mundo dos negócios é a exigência cada vez maior do consumidor (PEREZ, 2008; CORSATTO; HOFFMANN, 2013), que torna o mercado ainda mais competitivo (FIALHO, 2010), impelindo as organizações a turbinarem suas capacidades no processamento de informações, transformando-as em inteligência com fins de tomadas de decisões ótimas (TYSON, 1998; TRZECIAK; SCHENATTO; ABREU, 2008).

É nesse contexto que a Inteligência Competitiva (IC daqui em diante) se impõe como uma excelente ferramenta estratégica para a sobrevivência das organizações em cenário tão agressivo (SILVA, 2007; PORÉM; SANTOS; BELLUZZO, 2012; RODRIGUEZ; FONTANA, 2005). Sua indispensável utilização torna evidente que a apropriação de informação não é o suficiente para a decisão ótima visto que o principal desafio das organizações não é vencer o problema da assimetria de informação, mas saber selecionar e processar a exorbitante quantidade de informações da forma mais eficiente possível em relação ao seu concorrente (PORÉM; SANTOS; BELLUZO, 2012). 
Tal contingência nos leva a pressupor que as organizações que sobrevivem a mais tempo no mercado, mesmo que informalmente, devem possuir algum tipo de inteligência que os leva a competir em alto nível, haja vista a complexidade do cenário em que estão situados, pois de outra maneira, dificilmente conseguiriam se estabelecer por tanto tempo (RODRIGUES; RICCIARDI, 2007).

Apesar da forte presença da informalidade na criação de inteligência, diversas pesquisas identificaram que "cada vez mais, os executivos de grandes e médias empresas deixam de lado o velho hábito de administrar por instinto, para administrar baseado em informações processadas por sistemas de Tecnologia de Informação altamente sofisticados" (SIERRA; RODRIGUES, 2011, p. 2). É neste contexto, portanto, que se insere o estudo da maturidade no uso da IC.

Rodrigues e Riccardi (2007) realizaram uma pesquisa entre as 500 maiores empresas do Brasil propondo identificar quais os níveis de utilização de sistemas de informação de inteligência. Um mapa de maturidade com cinco níveis foi delineado, sendo elas: informal, formal, disciplinado, controlado e otimizado.

Por entender que sua aplicação seja apropriada para o perfil de organização a ser pesquisada, o objetivo deste artigo é caracterizar o nível de maturidade no uso de Inteligência Competitiva das óticas localizadas na rua das óticas, Centro de Cuiabá-MT conforme modelo proposto por Rodrigues e Riccardi (2007).

A rua das óticas, localizada na rua Cândido Mariano, região central de CuiabáMT, leva esse título por causa de um incomum conglomerado de óticas que, com o passar dos anos, se estabeleceu na região. Embora a pesquisa sobre aglomerações de empresas seja forte e consolidada, Ferreira e Farina (2014) afirmam não haver pesquisas que tenham utilizado a rua das óticas como objeto de análise. Os autores atribuem a si a primeira análise do conglomerado. Em sua análise concluíram que a aglomeração de óticas dessa região não chega a ser um cluster, ainda que tenha potencial para isso.

Quanto à relevância do estudo, é interessante observar que, apesar de se tratar de um conceito contextualmente imprescindível no que tange à estratégia e/ou sobrevivência das organizações, a IC é um campo de estudo ainda incipiente no Brasil (SIERRA; RODRIGUES, 2011). Do mesmo modo, pretende-se sensibilizar a pesquisa de Inteligência Competitiva em contexto de micros e pequenas empresas.

Para tanto, o artigo seguirá a seguinte sequência: além desta introdução, será apresentado o referencial teórico, focando-se na descrição do conceito de Inteligência Competitiva e níveis de maturidade em IC. Adiante serão descritos os procedimentos metodológicos, resultados e discussões, e, por fim, as considerações finais, limitações e recomendações de pesquisa. 


\section{Referencial Teórico}

\subsection{Inteligência Competitiva}

Quando Sakichi Toyoda, fundador da montadora Toyota, foi para os Estados Unidos nos anos 30 ele teve um objetivo em mente. Não era copiar o modelo americano, mas analisar suas fragilidades. A partir daí resultou o paradigma da produção flexível. Eis um clássico exemplo da utilização da Inteligência Competitiva como estratégia de ação. Os japoneses foram os primeiros a utilizarem a inteligência como ferramenta para o desenvolvimento de tecnologia e competição (MAURY, 1993; RICCARDI; RODRIGUES, 2003).

Por sua vez, os EUA iniciaram a utilização da IC como ferramenta organizacional apenas nos anos 80, bem mais tarde em relação aos japoneses. O marco foi a criação da SCIP - Sociedade dos Profissionais de Inteligência Competitiva. - SCIP (MENEZES; MARCIAL, 2001). Já em relação ao Brasil, a IC vem sendo utilizada desde os anos 90, vindo a se consolidar com a criação da ABRAIC - Associação Brasileira dos Analistas de Inteligência Competitiva (MENEZES; MARCIAL, 2001).

Inicialmente, na área militar, a inteligência era considerada uma capacidade para obtenção e análise de informações para possibilitar uma melhor decisão (COHEN, 1999). Atualmente, o conceito de inteligência possui um escopo maior. Pode ser um processo, mas também pode ser um produto - enquanto resultado desse processo - e ainda pode ser uma função organizacional, onde as pessoas estarão voltadas especificamente para essa atividade (CARVALHO; SANTOS, 1999).

$\mathrm{O}$ acirramento da competitividade no mundo dos negócios tem feito as empresas buscarem cada vez mais alternativas para sua sobrevivência. Uma delas é a permanente avaliação do ambiente com o intuito de colher informações para, com os recursos disponíveis, adotar medidas estratégicas aproveitando assim as oportunidades que surgem, bem como contornar as ameaças identificadas (GOMES; BRAGA, 2004).

Canongia (1998) afirma que um dos objetivos da IC é agregar valor à informação. Isso ocorre num processo onde há coleta, tratamento, análise e contextualização da informação para que enfim se transforme em inteligência. Já Valentim et al (2003) sustenta que a IC é o processo de investigação do ambiente onde a organização se encontra para a criação de oportunidades e redução de riscos os riscos. Também serve para diagnosticar o ambiente interno da empresa com o objetivo de estabelecer estratégias de ação tanto a curto quanto a longo prazo. 
Johnson (1995) citado por Carvalho e Santos (1999) define Inteligência Competitiva como "o deliberado e bem coordenado monitoramento dos seus competidores, onde quer que estejam ou quem quer que sejam, em um específico mercado".

Para Gilad e Gilad (1998), a IC preocupa com os processos e as ferramentas de coleta, análise e disseminação da inteligência permitindo então a tomada de decisão eficaz. Já Martendal (2004) define IC como sendo o acompanhamento contínuo das informações disponíveis no mercado, coletando, de forma sintetizada, os dados relevantes para a organização. Esses dados são distribuídos aos interessados, que irão traduzir e utilizar as informações da melhor maneira. Esse processo gera vantagem competitiva, redução de riscos e benefícios para o consumidor.

Enfim a IC é uma ferramenta que visa o estudo dos fatores que poderão tornar a organização mais competitiva diante de suas concorrentes (BARRANCOS; DUARTE, 2013).

Os tomadores de decisão de grande parte das empresas acabam trabalhando com elevada quantidade de dados em estado bruto, todavia, na verdade estão trabalhando com pouca informação e, consequentemente, uma quantidade menor ainda de inteligência. Este cenário pode ser revertido através do Sistema de Inteligência Competitiva, já que se trata de uma ferramenta que atenua tal problema, transformando dados em informação e esta, por sua vez em inteligência ativa (GOMES; BRAGA, 2004).

Na perspectiva de Maury (1993), a estruturação da IC dá-se em função de:

- Uma matriz consolidada de indicadores internos do empreendimento, a partir dos quais são determinadas as informações estratégicas para análise da concorrência;

- Instrumentos que caracterizam os fatores de vantagem competitiva, utilizando indicadores de desempenho e mapa dos conjuntos estratégicos, incorporando as dimensões de abrangência geográfica e de grau de especialização/verticalização;

- Modelos de avaliação de impactos em análise prospectiva, cujos principais referenciais metodológicos estão no "Profit Impact of Market Strategies (PIMS)"15 e no "Systemes et Matrices d'Impacts Croisés (SMICp. Os respectivos leques de aplicativos informáticos permitem identificar e hierarquizar as variáveis-chave e as estratégias dos atores;

- Modelo de portfólio empresarial, matriz de análise dos fluxos e da realização de valores financeiros, em função dos fatores de agregação de valor (posicionamento estratégico e concorrencial) e de evolução e mutações (análise prospectiva), estes agregados em quatro grupos: tecnologia e organização industrial; relações de concorrência; demanda e distribuição; conjuntura/regulamentações nacionais e internacionais. 
O monitoramento do ambiente externo (mercado, concorrentes, clientes) e do ambiente interno (processos, tecnologias, fornecedores e conhecimento humano) precisa ocorrer de forma direta e constante no suporte ao processo de tomada de decisões. A identificação dos fatores críticos de sucesso e o sistema de IC buscam coletar informações estratégicas para apoiar a tomada de decisão. Assim, estes se caracterizam como importantes instrumentos para auxiliar na gestão das organizações (COLAUTO et al., 2004).

Uma das formas de aperfeiçoar o processo de IC é monitorar continuamente os fatores de sucesso na consecução dos planos estratégicos (COLAUTO et al., 2004). Além disso, a IC auxilia na sistematização de dados, na análise sobre os concorrentes, na identificação das competências essenciais e no monitoramento dos fatores críticos de sucesso, que paralelamente promovem reflexos diretos no desempenho da organização (COLAUTO et al., 2004).

\subsection{Níveis de Maturidade em Inteligência Competitiva}

O processo de elaboração de um modelo de maturidade exige do pesquisador a adoção de um método que permita descrever os níveis e as dimensões a serem considerados como fases ou estágios da maturidade em IC. Independente dos modelos propostos são sempre mantidos um número de cinco níveis por serem considerados como ideais pela Software Engineering Institute -SEI (2006) citado por Zuquetto e Beltrame (2012), modificando-se apenas sua nomeclatura conforme definição dos criadores dos modelos. Por exemplo, Panizzon (2010) apud Zuquetto e Beltrame (2012) propôs os níveis, informal, básico, intermediário, avançado e padrão mundial.

A maturidade pode ser definida como "o grau em que as organizações utilizam as melhores práticas em seus processos e/ou sistemas internos" (ZUQUETTO; BELTRAME, 2012).

Para se construir um bom modelo de maturidade é imprescindível que se considere aspectos de caráter qualitativo e genérico e que devem ser colocados em ordem crescente de importância. Do menos para o mais importante deve-se considerar: i. a consciência e comunicação; ii. Políticas, planos e procedimentos; iii. Ferramentas e automação; iv. Habilidades e especialização; v. Responsabilidade e responsabilização e, vi. Definição de objetivos e medição (IT GOVERNANCE INSTITUTE, 2007, citado por ZUQUETTO; BELTRAME, 2012). 
É interessante observar que as empresas possuem melhor desempenho quando direcionam sua força em um "número gerenciável de áreas de processo em um dado momento", mas tais áreas necessitam sofisticar cada vez mais conforme a empresa vai melhorando (SOFTWARE ENGINEERING INSTITUTE, 2006 citado por ZUQUETTO; BELTRAME, 2012).

No modelo de Rodrigues \& Riccardi (2007), o nível 1, denominado "informal” se caracteriza por não ter norma, nem estrutura definida. Não há experiência em IC e também não existe infra-estrutura de um sistema de IC. No nível 2, o formal, já existe uma pequena experiência em IC. Os elementos existem, os processos funcionam, mas tudo carece de mais integração. No nível 3, o disciplinado, já existe uma experiência maior do que a vista no nível 2. Além disso, eleva-se substancialmente o processo de integração entre os elementos. No entanto, o empreendedorismo e as informações ainda são incipientes. Quanto ao nível 4, o controlado, há uma experiência em IC consolidada, os parâmetros e indicadores de desempenho bem definidos, já existe também uma auditoria e avaliação do retorno da IC e a inovação é sistematizada. Ainda há o último nível, o otimizado, neste nível o processo é ampliado e aperfeiçoado. A experiência é muito forte, e é acompanhado por um poderoso empreendedorismo corporativo (ZUQUETTO; BELTRAME, 2012; RODRIGUES; RICCARDI, 2007; RODRIGUES; SIERRA; RECHZIEGEL, 2014; SIERRA; RODRIGUES, 2011; KONO; RODRIGUES, 2014).

Esse modelo parte de esquemas precursores, principalmente o utilizado pelo trabalho de Goodrich (1987) apud Prestes (2009). Para tanto, eles pesquisaram as 500 maiores empresas do Brasil. Um passo importante foi a identificação do lócus funcional da IC, os objetivos, os motivos, as fontes, os processo, os usos, o papel da tecnologia da informação e o seu disciplinamento ético nessas organizações (SIERRA; RODRIGUES, 2011)

Observou-se que os motivos mais relevantes para a implantação de um sistema de IC foi a acirrada competição entre os concorrentes e a composição dos objetivos estratégicos alinhados à cultura de utilização de IC. Ainda assim, a pesquisa de Rodrigues e Riccardi (2007) identificou que a maioria das organizações apresentam IC incipiente. Tanto é que apenas $7 \%$ dessas empresas possuem sistemas de IC formalmente, ainda que a todas elas possuam algum tipo de mecanismo de busca e análise de informações externas. Foi a partir daí que os autores propuseram um mapa que descrevesse o nível de maturidade do sistema de IC (SIERRA; RODRIGUES, 2011; RODRIGUES; SIERRA; RECHZIEGEL, 2014).

Prescott (2002) apud Prestes (2009) afirma que a constituição da IC em uma empresa é um processo social; assim, uma cultura sustentada pela IC é construída gradualmente: primeiro, com a qualificação no trato das informações; depois com a 
formação da rede de contatos pessoais, e, finalmente, com a formalização de mecanismos para que as informações possam fluir adequadamente. Assim, é fundamental introduzir a avaliação de desempenho do sistema de IC, de forma a definir padrões para verificação da eficácia do sistema implantado. É também por meio destes padrões que os usuários de IC se motivam a bem utilizá-la (RODRIGUES; RICCARDI, 2007).

\subsection{Modelos de Maturidade}

A avaliação da maturidade na implantação e uso de sistemas teve como um dos pioneiros Philip Crosby (1999) que, tendo proposto um modelo aferidor para gerência da qualidade, abriu caminho para o estudo e desenvolvimento de modelos para análise de maturidade. A maturidade pode ser definida como a qualidade ou estado de estar maduro (BOUER; CARVALHO, 2005).

O Aferidor de Maturidade da Gerência de Qualidade desenvolvido por Crosby (1999) foi estudado e desenvolvido para diversas finalidades. A partir de então, modelos de medição de maturidade vêm sendo utilizados em diferentes áreas do conhecimento, como desenvolvimento de softwares, gerenciamento da qualidade, relacionamento com fornecedores, efetividade de pesquisa e desenvolvimento, desenvolvimento de produtos, inovação, design de produtos, confiabilidade de produtos, trabalho em equipes (FRASER; MOULTRIE; GREGORY, 2002), gerenciamento de contratos, processo de documentação, capabilidade de integração dos fatores humanos, capabilidade de pessoas, modelo de maturidade de projetos de cursos on line, processo de gestão da cadeia de suprimentos, (LOCKAMY; McCORMACK, 2004), gerenciamento de projetos (BOUER; CARVALHO, 2005; LOCKAMY; McCORMACK, 2004).

O uso da palavra Maturidade, referindo-se ao gerenciamento de projetos, implica que as capacidades de gerenciamento devem evoluir ao longo do tempo com o objetivo de produzir de forma sistemática e contínua resultados de sucesso no gerenciamento de projetos. Maturidade em projetos pode também significar que uma organização está perfeitamente condicionada para gerenciar seus projetos. Quando aplicado a uma organização, este conceito significa que esta se encontra em perfeitas condições para alcançar seus objetivos (BOUER; CARVALHO, 2005).

O conceito de maturidade de processo sugere que um processo pode ser estruturado a partir de estágios ou níveis de evolução distintos, que podem ser objetivamente descritos, claramente definidos, gerenciados, mensurados e controlados ao longo do tempo (FRASER; MOULTRIE; GREGORY, 2002; LOCKAMY; McCORMACK, 2004; SILVEIRA, 2009). 
Os modelos de avaliação de maturidade podem servir à avaliação da maturidade de projetos, como é o caso do modelo PMMM (BOUER; CARVALHO, 2005), do modelo OPM3 (SILVEIRA, 2009). Neste caso, os processos possuem um ciclo de vida (BOUER; CARVALHO, 2005), apresentando início, meio e fim. Outra utilidade para os modelos de avaliação de maturidade é a avaliação da maturidade de processos, como o modelo criado por Crosby (1999), os modelos CMM (BOUER; CARVALHO, 2005), e o modelo COBIT (ISACA, 2009). Os processos possuem característica cíclica, sendo continuamente realimentados e melhorados.

O modelo proposto neste trabalho será um modelo para avaliação do processo de inteligência competitiva, um processo cíclico. Os modelos de maturidade podem ser do tipo contínuo ou do tipo por estágio. Quando a medição é relativa à maturidade dentro de cada nível do processo, o modelo de maturidade é chamado contínuo. Nos modelos contínuos, diferentes atividades são niveladas em diferentes níveis. Quando a medição de maturidade consiste em uma classificação sobre em que nível o processo se encontra, o modelo é chamado modelo por estágio. Este tipo de modelo permite avaliar o que falta para atingir o próximo estágio do processo. Assim, é possível codificar o que pode ser considerado como boa prática ao longo dos estágios intermediários (FRASER; MOULTRIE; GREGORY, 2002).

Embora existam diversos modelos de avaliação de maturidade, algumas características aparecem comumente na maior parte deles. Fraser, Moultrie e Gregory (2002) salientam que a definição de áreas de dimensões ou processos em diversos estágios (ou níveis) de maturidade, e a descrição de características de desempenho esperado para os diversos níveis, aparece na maioria dos modelos (FRASER; MOULTRIE; GREGORY, 2002). Para Silveira (2009), a maior contribuição trazida pelos modelos de avaliação de maturidade não é definir em que nível a empresa se encontra, mas sim o que deve ser feito para assegurar a continuidade do seu desenvolvimento e a melhoria contínua e controlada de seus processos (SILVEIRA, 2009).

A avaliação de maturidade auxilia na quantificação de grandezas relacionadas às diferentes áreas onde é aplicada e pode servir como ferramenta de auxílio no desenvolvimento daquelas áreas. Foram apresentados neste tópico alguns conceitos referentes aos modelos de maturidade. No tópico a seguir serão descritos alguns dos modelos de maturidade. 
O modelo desenvolvido por Crosby (1999), o Aferidor da Gerência da Qualidade, trata-se de uma escala para a medição da maturidade da gerência da qualidade. Nas áreas de desenvolvimento e engenharia de software, os modelos CMM (Capability Maturity Model) e CMM-I (Capability Maturity Model Integrated), têm sido amplamente utilizados. Além dos modelos utilizados nas áreas de desenvolvimento e engenharia de software, existem modelos para a avaliação de maturidade em gerenciamento de projetos de natureza mais abrangente e genérica. Dentre estes, se destacam o Project management Maturity Model (PMMM) e o Organizational Project Management Maturity Model (OPM3). No gerenciamento das estratégias das organizações, o alinhamento da Tecnologia de Informação (TI) com as estratégias organizacionais podem ser apoiados pelo modelo Control Objectives for Information and related Technology (COBIT).

Estas são algumas das áreas que podem se beneficiar dos modelos de avaliação de maturidade. A partir da análise desses modelos, será proposto o modelo que será utilizado para os fins deste trabalho. Os modelos citados serão apresentados e descritos a seguir.

\subsubsection{Modelo Aferidor da Gerência da Qualidade de Crosby}

O modelo Aferidor de Maturidade da Gerência de Qualidade desenvolvido por Crosby (1999) tinha como finalidade avaliar a maturidade das categorias de gerenciamento da qualidade. Para isso, as categorias de análise foram classificadas segundo cinco estágios: 1) incerteza, 2) despertar, 3) esclarecimento, 4) sabedoria e, estágio 5) certeza. Cada categoria é classificada segundo o estágio de maturidade em que se encontra. O estabelecimento das categorias é feito segundo os objetivos da área da qualidade. O conhecimento da maturidade de cada categoria permite compreender o que será necessário aperfeiçoar visando atingir o próximo nível de maturidade.

\subsubsection{Modelos CMM e CMM-I}

Os modelos mais utilizados nas áreas de desenvolvimento e engenharia de software são o CMM e o CMM-I. Baseados nos conceitos de níveis de maturidade e requisitos estruturais de áreas-chaves de processo, esses modelos têm sido utilizado nas organizações para avaliações do nível de maturidade e capacidade em gestão de projetos de software (BOUER; CARVALHO, 2005). O CMM foi desenvolvido por pesquisadores do Instituto de Engenharia de Software (SEI) da Carnegie-Mellon University, em 1986 (SILVEIRA, 2009) atendendo à necessidade de sistematizar os processos críticos, criando padrões de concepção e desenvolvimento de softwares para sistemas de defesa. O desenvolvimento do CMM teve por base o modelo apresentado por Crosby (1999) (SILVEIRA, 2009). Cada estágio de desenvolvimento (ou nível de maturidade) distingue uma capacidade da organização desenvolvedora de software. Em cada nível de 
maturidade são identificadas Key Process Áreas - KPA's (áreas-chave de processo). A organização busca o aperfeiçoamento para atingir seus objetivos à medida que busca desempenhar os requisitos definidos nas KPA's (RAMANUJAN; KESH, 2004). O CMM apresenta os seguintes níveis de maturidade (PAULK et al, 1993, apud FRASER; MOULTRIE; GREGORY, 2002; BOUER; CARVALHO, 2005; SILVEIRA, 2009): 1) inicial, 2) repetível, 3) definido, 4) gerenciável e 5) otimizado.

O modelo CMM-I foi desenvolvido visando integrar os modelos de melhoria de processos de diferentes áreas. Tornava-se caro e ineficiente utilizar diferentes modelos nos diferentes processos controlados pelas organizações. Visando a integração dos modelos foi desenvolvido, sobre as melhores práticas do CMM, o modelo CMM-I. Sua aplicação não é limitada a uma só área ou disciplina. Suas áreas de uso incluem gerenciamento de projetos, engenharia de software, engenharia de sistemas, desenvolvimento integrado de produtos e processos, entre outras (RAMANUJAN; $\mathrm{KESH}, 2004)$.

O modelo CMM-I apresenta a representação por estágios e também a contínua. $\mathrm{Na}$ versão por estágios, para cada nível de maturidade são definidos conjuntos de requisitos estruturais das $K P A$ 's. Esta versão, de forma análoga ao modelo CMM, tem cinco níveis de maturidade: 1) inicial, 2) gerenciado, 3) definido, 4) quantitativamente gerenciado, 5) otimizado (BOUER; CARVALHO, 2005). A versão contínua do modelo CMM-I tem como resultado um perfil de maturidade de cada uma das KPAs, resultando em um perfil de maturidade da organização. Este modelo apresenta seis níveis de capacitação (SHRUM, 2000, apud FRASER; MOULTRIE; GREGORY, 2002; BOUER; CARVALHO, 2005) - Nível 0 - incompleto, 1 - realizado, 2 - gerenciado, 3 - definido, 4 - quantitativamente gerenciado, 5 - otimizado.

\subsubsection{Modelo PMMM}

O modelo PMMM possui um escopo e abrangência adequados para a avaliação de maturidade em gestão de projetos de natureza mais genérica do que projetos voltados à área de tecnologia de informação. O modelo introduz ferramentas de Benchmarking para mensurar o progresso de uma organização ao longo de um modelo de maturidade. Cinco são os níveis de desenvolvimento para o alcance da plena maturidade em gerenciamento de projetos: 1) linguagem comum, 2) processos comuns, 3) metodologia singular, 4) benchmarking, 5) melhoria contínua. Para cada nível são definidas fases específicas que determinam a maturidade (BOUER; CARVALHO, 2005).

Este modelo combina a estrutura de áreas do PMBoK (Project Management Body of Knowlwdge) com a estrutura de níveis de maturidade do modelo CMM. Sua evolução segue os estágios Conhecimento básico, Processos definidos, Processos controlados e Processos aprimorados (BOUER; CARVALHO, 2005). 


\subsubsection{Modelo OPM3}

O objetivo do OPM3 é permitir às empresas a visualização das capacidades necessárias para a implementação de suas estratégias com consistência e previsibilidade. $\mathrm{O}$ modelo possibilita às empresas produzir e reproduzir com sucesso e de forma consistente ao longo do tempo um alto desempenho no gerenciamento de projetos (SILVEIRA, 2009).

O modelo OPM3 se utiliza do conceito de ciclo de vida do projeto, presente no $P M B o K$ e enfoca os principais processos envolvidos no gerenciamento de projetos: inicialização, planejamento, execução, controle e fechamento. $\mathrm{O}$ modelo identifica também quatro estágios de melhoria: padronização, mensuração, controle e melhoria contínua. Três são os domínios relevantes à gestão do projeto organizacional: projeto, programa e portfólio (BOUER; CARVALHO, 2005).

\subsubsection{Modelo COBIT}

O modelo COBIT (Control Objectives for Information and related Technology) é destinado a controlar e medir o desempenho da Tecnologia de Informação (TI) das empresas direcionando a TI ao atendimento das necessidades do negócio. O modelo habilita as organizações, baseando-se em critérios e processos de avaliação uniformes, a avaliar como estão sendo gerenciados seus recursos. Além disso, permite a comparação da empresa com outras empresas (ISACA, 2009).

O modelo COBIT tem foco na governança das áreas de alinhamento estratégico, entrega de valor, gerenciamento de recursos, gerenciamento de riscos, e medição de desempenho. Além desse foco, também o modelo COBIT possibilita a realização de benchmarking, de estabelecimento de objetivos e métricas e de controles dos objetivos das atividades relacionadas à Tecnologia de Informação. Trata-se de um modelo de processo genérico que representa todos os processos normalmente usados nas funções de Tecnologia de Informação (ISACA, 2009). Permite, ainda, à alta gerência mensurar a eficiência da gestão do processo de governança e direcionar seus esforços para a melhoria dos domínios com menor maturidade, garantindo dessa forma o alinhamento dos objetivos estratégicos da organização ao controle dos processos.

O modelo COBIT especifica os domínios: (i) planejamento e organização, (ii) implementação, (iii) entrega e suporte, além de (iv) monitoração e avaliação, para que sirvam de guia no atendimento dos objetivos específicos da organização. Propõe também um conjunto de processos agrupados nos domínios. Para cada processo, é definido um conjunto de objetivos de controle que são monitorados e controlados. O grau de maturidade dos processos é determinado pela análise do desempenho nos objetivos (FIALHO, 2010). 
Os objetivos de controle são avaliados e a eles é atribuído um nível segundo a sua maturidade. A análise do desempenho e a atribuição de níveis de maturidade permitem que seja possível a compreensão da situação atual da organização e do que ainda necessita ser aperfeiçoado para o alcance das metas estratégicas da organização. Para cada objetivo, é atribuído um nível segundo a escala: 0 -inexistente, 1 - inicial, 2 - repetível, 3 -definido, 4 - gerenciado e 5 - otimizado. Cada um desses níveis tem sua própria descrição e busca descrever a situação em que se encontra o processo avaliado (FIALHO, 2010).

\section{Procedimentos Metodológicos}

A pesquisa foi realizada na perspectiva de buscar conhecimento a respeito do nível de maturidade organizacional em Inteligência Competitiva. Assim foi realizado um breve levantamento bibliográfico a respeito do tema maturidade organizacional em inteligência competitiva. Na sequência foram analisadas seis empresas do ramo de óticas, localizadas na rua das óticas de Cuiabá. A amostra seguiu o critério de conveniência em função da disponibilidade dos seus respectivos gerentes para a entrevista. Esta entrevista seguiu o questionário proposto por Rodrigues e Ricardi (2007) (conforme Anexo A).

As perguntas foram adaptadas visando uma melhor compreensão dos termos utilizados. Considerando o tamanho da amostra e abordagem utilizada, esta pesquisa pode ser considerada como qualitativa. Não se utilizou métodos e técnicas estatísticas, apresentando uma estrutura descritiva, sendo o processo e seu significado os focos principais da abordagem (SILVA; MENEZES, 2005). Neste caso, buscar-se-á esclarecer quais os níveis de maturidade em IC das empresas analisadas.

A implementação de um processo de Inteligência Competitiva requer o entendimento do funcionamento de suas fases por parte dos responsáveis pela tomada de decisão nas empresas. A identificação de padrões mais ou menos previsíveis no desenvolvimento daqueles processos podem auxiliar no balizamento eficaz da ação gerencial (SILVEIRA, 2009). A maturidade do processo pode ser avaliada através do desempenho alcançado em cada uma dessas fases: Planejamento e identificação das necessidades, Coleta, Análise, Disseminação das informações e Feedback. A partir do conhecimento da maturidade em que se encontra cada estágio, seja na implantação ou no uso da Inteligência Competitiva, as empresas poderão também conhecer os próximos passos necessários à sua evolução.

Dessa forma, a proposição deste trabalho é que a avaliação do uso de Inteligência Competitiva nas empresas pode ser adequadamente apoiada pela aplicação de um modelo de maturidade. 
Quanto a metodologia proposta por Rodrigues e Riccardi (2007) existem cinco níveis de maturidade organizacional sendo em nível crescente de importância o Nivel 1 Informal, Nível 2 Formal, Nível 3 Disciplinado, Nível 4 Controlado e Nível 5 Otimizado. O entendimento de cada um dos níveis será detalhado a seguir.

- Nível 1 - INFORMAL - Incipiente, sem norma ou estrutura definida. Nenhuma experiência em IC. Existência de infraestrutura de TI, mas não orientada para IC.

- Nível 2 - FORMAL - Estruturado e normatizado. Existência de infraestrutura de TI voltada para a IC. Pouca experiência em IC. Os elementos constituintes estão criados e os processos de funcionamento estão definidos. Elementos não funcionam integrados.

- Nível 3 - DISCIPLINADO - Incorporado e praticado. Experiência moderada em IC. Equipes observam procedimentos padrões definidos. Elementos constitutivos funcionam de forma integrada. Empreendedorismo e inovação são incipientes.

- Nível 4 - CONTROLADO - Avaliado pelo desempenho. Experiência em IC consolidada. Parâmetros e indicadores de desempenho definidos. Auditamento e avaliação do retorno da IC. Inovação é sistematizada.

- Nível 5 - OTIMIZADO - Ampliado e aperfeiçoado. Forte experiência em IC. IC suporta os processos decisórios e de inovação estratégica. Forte empreendedorismo corporativo. Suporte incisivo à GC.

\section{Resultados e Discussão}

As informações coletadas das entrevistas com os gerentes e decisores das seis óticas abordadas revelou que os processos de coleta e análise de dados que serão utilizados para tomada de decisão estratégica são feitos de forma bem elementar.

No caso do modelo de Rodrigues e Riccardi (2007), os questionários devem ser organizados e interpretados visando delinear os "componentes da Inteligência Competitiva". Cada nível de maturidade no uso da Inteligência Competitiva apresenta seus próprios componentes. Para o nível 1 (sem norma escrita; estrutura identificada, nenhuma experiência em IC; TI não orientada à IC), para o nível 2 (norma escrita; estrutura definida; TI orientada à IC; pouca experiência em IC; Elementos e processos criados e definidos; elementos não integrados), para o nível 3 (IC incorporado e praticado; experiência moderada em IC; procedimentos e padrões definidos e observados; elementos integrados; empreendedorismo e inovação incipientes), para o nível 4 (avaliação de desempenho; experiência consolidada em IC; parâmetros e indicadores de desempenho; auditoria e avaliação de retorno de IC; inovação sistematizada) e, por fim, para o nível 5 (IC ampliado e aperfeiçoado; forte experiência em IC; IC suporta processos decisórios e inovação em IC; forte empreendedorismo corporativo; suporte incisivo à gestão do conhecimento). 
Nenhuma das óticas entrevistas apresentou algum tipo de norma escrita orientado para Inteligência Competitiva, não possuem estrutura para IC, não possuem experiência em IC, e tampouco sua tecnologia de informação é orientada para a IC.

Quando entram em contato com o conceito de Inteligência Competitiva, ao serem questionados se este conceito é aplicado na empresa, a resposta é positiva. No entanto, quando é solicitado exemplos de como isso é feito, as respostas variam entre buscas aleatórias na internet, principalmente nas redes sociais, pesquisa de opinião com clientes que adentram a loja, estar antenado em relação à estratégia de marketing dos concorrentes, etc.

Ao serem perguntados sobre a existência de algum sistema organizado de IC, os gerentes de cinco óticas foram categóricos em sua negativa, um deles, no entanto, disse que utilizava um sistema com dados detalhados dos clientes, no entanto, deixou claro que o banco de dados não era exclusivo para uso de IC.

Ainda que tudo seja feito de maneira rudimentar e elementar, cinco dos seis entrevistados consideram o processo de IC de extrema importância para a tomada de decisão estratégica.

A maneira como os gerentes selecionam as informações para uso estratégico basicamente segue a percepção pessoal, sendo acompanhada de experiência no mercado obtida por meio de erros e acertos. Reconhecem o caráter informal do processo de IC, mas não abrem mão de considerar sua empresa como inovadora de alguma forma com seus serviços e produtos. O processo de IC é, portanto, rudimentar, feito apenas pelos gerentes ou decisores e, de maneira não sistemática, e sem o uso de uma TI específica para isso.

Seguindo a metodologia de Rodrigues e Riccardi (2007) adaptado por Sierra e Rodrigues (2011), percebeu-se que as óticas entrevistadas seguem o nível de maturidade 1 - Informal conforme mapa descrito no quadro 01 abaixo:

Ou seja, as óticas pesquisadas da rua das óticas não possuem norma escrita para a tomada de decisões estratégicas, tem estrutura identificada, não possuem experiência em IC e sua tecnologia de informação não está orientada para a IC. Isso vai de encontro com os resultados de outra pesquisa, (SIERRA; RODRIGUES, 2011), onde pode se verificar que os níveis de maturidade em IC, obtidos de uma instituição financeira também foram preponderantes para o nível 1.

Entre as poucas pesquisas que aplicam o modelo de Rodrigues e Riccardi (2007) no Brasil, a maioria deles observou-se uma proeminência do nível de informalidade no uso de sistemas em IC. Por exemplo, Fialho (2010), avaliando IC em empresas na área de construção civil na Cidade de Porto Alegre, afirma que as informações para tomada de decisões ocorrem somente entre os diretores da organização e inexiste um sistema estruturado para IC. Marcola e Politano (2015), pesquisando em empresa do segmento de 
infraestrutura também afirmam que as tomadas de decisões e as disseminações das informações estão centralizadas pela diretoria sendo a IC caracterizada como informal.

Quadro 01 - Mapa do Nível de Maturidade em Inteligência Competitiva

\begin{tabular}{|c|c|c|}
\hline Nível & Componente & Identificação \\
\hline 1 - Informal & $\begin{array}{l}\text { Sem Norma escrita } \\
\text { Estrutura Identificada } \\
\text { Nenhuma Experiência em IC } \\
\text { TI não orientada à IC }\end{array}$ & \\
\hline 2 - Formal & $\begin{array}{l}\text { Norma Escrita } \\
\text { Estrutura Definida } \\
\text { TI Orientada à IC } \\
\text { Pouca Experiência em IC } \\
\text { Elementos e Processos Criados e Definidos } \\
\text { Elementos Não Integrados }\end{array}$ & \\
\hline 3 - Disciplinado & $\begin{array}{l}\text { Incorporado e Praticado } \\
\text { Experiência Moderada em IC } \\
\text { Procedimentos Padrões definidos e observados } \\
\text { Elementos Integrados } \\
\text { Empreendedorismo e Inovação incipientes }\end{array}$ & \\
\hline 4-Controlado & $\begin{array}{l}\text { Avaliação de Desempenho } \\
\text { Experiência Consolidada em IC } \\
\text { Parâmetros e Indicadores de Desempenho } \\
\text { Auditoria e avaliação de retorno de IC } \\
\text { Inovação Sistematizada }\end{array}$ & \\
\hline 5 - Otimizado & $\begin{array}{l}\text { Ampliado e Aperfeiçoado } \\
\text { Forte Experiência em IC } \\
\text { IC suporta processos decisórios e inovação em IC } \\
\text { Forte Empreendedorismo Corporativo } \\
\text { Suporte incisivo à Gestão do Conhecimento }\end{array}$ & \\
\hline
\end{tabular}

Fonte: Elaboração própria. 
Por se tratar de micro e pequenas empresas, é natural que encontrem mais dificuldades na implantação de sistemas em IC. Em pesquisas com organizações desse perfil, Oliveira et al. (2015) aponta que as micro e pequenas empresas encontram sérios obstáculos para desenvolverem a IC por estarem associados quase que exclusivamente à visão dos proprietários da organização, deixando de lado a percepção de significância dos Stakeholders. Na pesquisa de Oliveira et al. (2015) inexiste uma sistematização das informações que apoiem a IC. Já Hoffmann e Chemalle (2013) ao estudarem as micro e pequenas empresas de Arranjo Produtivo Local (APL), ao abordar os problemas, necessidades e oportunidades comuns na busca por informações, apontaram que o problema não é o de volume de informações, mas metodologias que proporcione separar e reter as informações para a tomada de decisão. Ou seja, as maiores dificuldades em IC nas MPE's não estão na geração de informações, mas na inexistência de ferramentas adequadas para criar valor a partir dessas informações.

Gerar informações para tomada de decisões é importante, pois conforme Silva e Menezes (2005) as rápidas mudanças que ocorrem no ambiente competitivo, demandam informações confiáveis e disponíveis na mão do gestor, pois quanto maior a precisão das informações, maiores serão a possibilidades de tomadas de decisões acertadas.

Por fim, é importante salientar que a pesquisa em maturidade precisa amadurecer, tendo em vista a incipiência da quantidade de publicações, considerada muito baixa até o presente momento, com o complicador de não ter havido uma abordagem sobre as particularidades do setor de serviços de forma mais específica e aprofundada (CRUZ; PAULINO; PAIVA, 2015).

\section{Considerações Finais}

Esta pesquisa teve como objetivo caracterizar o nível de maturidade no uso de Inteligência Competitiva de seis óticas da rua das óticas conforme modelo proposto por Rodrigues e Riccardi (2007).

Evidenciou-se que as óticas apresentaram o nível 1 de maturidade, podendo ser classificadas como informais. O quesito "norma escrita" para o uso de IC, apresenta-se completamente ausente nas óticas entrevistadas. Quanto ao quesito "identificação da estrutura", observou-se a existência de uma estrutura em potencial para coleta de informação, porém muito centrada nos proprietários e gerentes da empresa, sem a disseminação da informação para outros setores. Já em relação ao quesito "experiência em IC", não foi encontrada nenhum conhecimento que pudesse ser caracterizado como básico para ser considerado experiência, mesmo que a nível rudimentar. Logo, a TI também não é orientada para IC, consolidando em todos os quesitos determinados pelo modelo a característica de informalidade no nível de maturidade. 
Nesse estudo há duas limitações importantes. A primeira é a dificuldade em extrapolar/generalizar os resultados da pesquisa para todas as empresas do setor em função de se tratar de um estudo com amostra pequena. Além disso, as informações foram coletadas por meio da entrevista de uma pessoa, que representava a empresa, normalmente o gestor. Esse método acaba sujeito à interpretação subjetiva da pessoa entrevistada. Para estudos futuros recomenda-se uma pesquisa quantitativa com maior quantidade de amostras visando evidenciar qual o conhecimento dos gestores e decisores em relação à Inteligência Competitiva e os níveis de maturidade.

\section{Referências}

BARRANCOS, J. E.; DUARTE, E. N. Inteligência Competitiva e as Práticas de Gestão do Conhecimento no Contexto da Administração e da Ciência da Informação: revelações da produção científica. Encontros Bibli, v. 18, n. 38, 2013.

BOUER, R.; CARVALHO, M. M. de. Metodologia singular de gestão de projetos: condição suficiente para a maturidade em Gestão de Projetos? Prod. online. v. 15, n. 3, p. 347-361, 2005.

CANONGIA, C. Sistema de inteligência: uso da informação para dinamização, inovação e competitividade. In: Simpósio Internacional de Propriedade Intelectual, Informação e Ética. Florianópolis: UFSC, 1998.

CARVALHO, H. G. de, SANTOS, N. dos. A estreita relação entre gestão do conhecimento e inteligência competitiva. I Workshop Gestão do Conhecimento e Inteligência Competitiva. Rio de Janeiro: CIET/SENAI, 1999.

COHEN, D. Não vejo ninguém na minha frente. Revista Exame, nº 690, jun. 1999.

COLAUTO, R. D.; GONÇALVES, C. M.; BEUREN, I. M.; SANTOS, N. dos. Os fatores críticos de sucesso como suporte ao sistema de Inteligência Competitiva. Revista de Administração Mackenzie. v. 5, n. 2, 2004.

CORSATTO, C. A. HOFFMANN, W. A. M. Gestão do Conhecimento e Inteligência competitiva: delineamento de estratégias de competitividade e inovação para pequenas empresas. Encontros Bibli: revista eletrônica de biblioteconomia e ciência da informação, v. 18, n. 38, set/dez, 2013.

CRUZ S.; PAULINO S.; PAIVA D. Service Innovation dynamics in solid waste sector: CDM landfill projects. XXV RESER conference "Service development and innovation for prosperity and human well-being in the 21st century", Copenhagen, 10-12 September, 2015.

CROSBY, P. B. Qualidade é investimento.Trad. Áurea Weisenberg. 7. ed. Rio de Janeiro: José Olympio, 1999.

FERREIRA, H. L.; FARINA, M. C. Estudo das relações entre empresas por meio da análise de redes sociais: o caso da rua das óticas no município de Cuiabá-MT. Caderno Profissional de Administração da UNIMEP, v. 4, n. 2, p. 103-119, 2014.

FIALHO, A. dos S. Análise do uso da Inteligência Competitiva no setor da construção de imóveis residenciais na cidade de Porto Alegre. Dissertação de Mestrado. Pontifícia Universidade Católica do Rio Grande do Sul. Faculdade de Administração, Contabilidade e Economia. Porto Alegre, 2010. 
FRASER, P.; MOULTRIE, J.; GREGORY, M. The use of maturity models / grids as a tool in assessing product development capability. IEEE Institute of Electrical and Electronics Engineers, 2002.

GILAD, B; GILAD, T. The Business Intelligence Sistem: a new tool for competitive advantage. New York: American Managemente Association, 1988.

GOMES, E; BRAGA, F. Inteligência Competitiva: como transformar informação em um negócio lucrativo. $2^{\text {a }}$ ed. Rio de Janeiro: Elsevier, 2004.

HOFFMANN, W. A. M.; CHEMALLE, K. E. Acesso e uso de inteligência competitiva em micro e pequenas empresas de arranjos produtivos locais. Departamento de Ciência da Informação Universidade Federal de São Carlos, 2013.

ISACA. The Risk IT Framework. Rolling Meadows, IL: ISACA, 2009.

KONO, C.; RODRIGUES, L. C. Inteligência Competitiva, computação em nuvem e inovação em pequenas empresas. 11th International Conference on Information Systems and Technology Management - CONTECSI, São Paulo, 2014.

LOCKAMY, A.; MCCORMACK, K. The development of a supply chain management process maturity model using the concepts of business process orientation. Supply Chain Management: An International Journal, v. 9, n. 4, p.272-278, 2004.

MARCOLA, J. A.; POLITANO, P. R. Inteligência competitiva: estudo de caso em uma empresa que atua no segmento de infraestrutura. XXXV Encontro Nacional de Engenharia de Produção. Perspectivas Globais para a Engenharia de Produção Fortaleza, CE, Brasil, 13 a 16 out. 2015.

MARTENDAL, F. L. A existência de inteligência competitiva na tomada de decisão estratégica, nas grandes empresas têxteis, do segmento cama, mesa e banho, de Santa Catarina. Dissertação de Mestrado. Programa de Pós-Graduação em Administração - PPGAd/FURB - Universidade Regional de Blumenau. 2004.

MAURY, P. Inteligência competitiva e decisão empresarial. Ci. Inf., Brasília, v. 22, n. 2, p. 138 141, maio/ago, 1993.

MENEZES, J. G.; MARCIAL, E. C. A Inteligência competitiva e o quarto canal. In: Workshop Brasileiro de Inteligência Competitiva, 2001. Seminário Catarinense de Gestão do Conhecimento, v. 3, 2001, Florianópolis. Anais. Florianópolis: SENAI, 2001.

OLIVEIRA, P. H.; PECHIM, D. M.; MEYER, B. M.; PAULO, B. M.; SANTOS, L. M. O. D. Inteligência Competitiva no Contexto das Micro e Pequenas Empresas do Setor Imobiliário. Caderno Profissional de Administração da UNIMEP, v. 5, n. 2, p. 46-62, 2015.

PEREZ, C. Consumidores mais complexos e exigentes: Um desafio ético e estético para as marcas contemporâneas. eGesta - Revista Eletrônica de Gestão de Negócios, v. 4, n. 3, jul-set. 2008.

PORÉM, M. E.; SANTOS, V. C. B. dos; BELLUZZO, R. C. B. Vantagem competitiva nas empresas comtemporâneas: a informação e a inteligência competitiva na tomada de decisões estratégicas. Intexto, Porto Alegre, UFRGS, n. 27, dez. 2012.

PRESTES, A. R. A Introdução do conceito e a aplicação de Inteligência Competitiva em Hospitais de Caxias do Sul. Dissertação de Mestrado. Universidade de Caxias do Sul. Programa de Pós-Graduação em Administração. Caxias do Sul, 2009.

RAMANUJAN, S.; KESH, S. Comparison of knowledge management and CMM/CMM1 implementation. Journal of American Academy of business, v. 4, n. 1/2, p. 271-277, 2004

RICCARDI, R.; RODRIGUES, L. C. Inteligência Competitiva: en los negócios y en lãs organizações. Buenos Aires: Macchi, 2003. 
RODRIGUES, L. C., RICCARDI, R. (2007). Inteligência Competitiva - nos Negócios e Organizações. Maringá (PR): Ed. Unicorpore, 2007.

RODRIGUES, L. C., SIERRA J. C. V.; RECHZIEGEL, W. Maturidade Organizacional em Inteligência Competitiva - O Caso de uma Instituição Financeira Brasileira. Revista de Ciências da Administração, v.16, n. 38, p. 126-139, 2014.

RODRIGUES, M. V. R.; FONTANA, E. W. Inteligência Competitiva: Nível de uso e influência nas receitas nos pequenos negócios exportadores. READ - Ed. 45, v. 11, n. 3, mai-jun, 2005.

SIERRA, J. C. V.; RODRIGUES, L. C. Maturidade Organizacional em Inteligência Competitiva - o caso de uma instituição financeira brasileira. Dissertação de Mestrado - UNINOVE, São Paulo, 2011.

SILVA, H. M. da. Gestão do Conhecimento e Inteligência Competitiva em Organizações: Uma abordagem conceitual. Revista de Iniciação Científica da FFC, v. 7, n. 1, 2007.

SILVA, E. L. da; MENEZES, E. M. Metodologia da pesquisa e elaboração de dissertação. 4. ed. rev. Atual. Florianópolis: UFSC, 2005.

SILVEIRA, V. N. S. Os modelos multiestágios de maturidade: um breve relato de sua história, sua difusão e sua aplicação na gestão de pessoas por meio do People Capability Maturity Model (P-CMM). RAC, Curitiba, v. 13, n. 2, art. 4, p. 228-246, 2009.

TYSON, K. Guide to competitive intelligence: gathering, analyzing, and using competitive intelligence. Chicago: Kirk Tyson, 1998.

TRZECIAK, D. S.; SCHENATTO, F. J. A.; ABREU, A. F. Inovação e Inteligência Competitiva: Uma abordagem integradora sob o enfoque dos processos. XXVIII Encontro Nacional de Engenharia de Produção. A integração de cadeias produtivas com a abordagem da manufatura sustentável. Rio de Janeiro, 2008.

VALENTIM, M. L. P. LENZI, L. A. F.; CERVANTES, B. M. N.; CARVALHO, E. L. de; GARCIA, H. D.; CATARINO, M. E.; TOMAÉL, M. I. O processo de inteligência competitiva em organizações. DataGramaZero, Rio de Janeiro, v. 4, n. 3, p. 1-23, jun. 2003.

ZUQUETTO, R. D.; BELTRAME, A. Modelo de Maturidade em Inteligência Competitiva. Global Manager Acadêmica, v. 1, p. 1-19, 2012. 


\section{ANEXO A - Questionário a ser aplicado para análise do Nível de Maturidade (RODRIGUES \& RICCIARDI, 2007)}

1) As atividades de inteligência competitiva congregam a analise a coleta, seleção e análise de dados, que são transformados em informações, que por sua vez, podem subsidiar a tomada de decisões e a formulação de estratégias. Você identifica a realização das atividades acima em sua área/empresa? As atividades desempenhadas em sua área/empresa têm relação com esses conceitos? Exemplifique e, se possível, relacione sua atividade com as funções de inteligência competitiva descrita acima.

2) $\mathrm{Na}$ empresa, como você percebe a função das atividades descritas acima como inteligência competitiva? Elas constituem um sistema organizado de inteligência?

3) Em sua opinião, as informações produzidas a partir dos dados coletados no ambiente externo (ameaças ou oportunidades) sensibilizam os níveis estratégicos da organização na tomada de decisões e/ou na formulação das estratégias?

4) Na estrutura organizacional e hierárquica de sua área/empresa existe uma posição para a inteligência competitiva? E na hierarquia da empresa? Descreva seu posicionamento.

5) Você entende que os processos e atividades de inteligência competitiva da forma como acontecem em sua are/empresa caracterizam um sistema mais formal ou informal? Justifique.

6) Como está estruturada a Inteligência Competitiva em sua área/empresa?

7) Qual o contingente de pessoas envolvidas?

8) Essas pessoas são todas da empresa, ou a inteligência competitiva está compartilhada com empresas parceiras?

9) As pessoas que compõem a Inteligência Competitiva são provenientes de várias áreas? A equipe é multifuncional e interdisciplinar?

10) Quais os papéis de cada pessoa nas funções (coleta, seleção, análise e produção) de Inteligência Competitiva? Eles estão bem definidos e padronizados?

11) Existe um planejamento dessas atividades ou elas acontecem em reação a estímulos externos e dos gestores?

12) Existe uma norma escrita sobre o sistema e os processos de Inteligência Competitiva?

13) Qual é a participação da área de TI para sustentação do sistema de Inteligência Competitiva?

14) Como a sua área/empresa coleta as informações? Como é feita a gestão da informação em termos de confiabilidade e acuidade?

15) Para satisfazer as necessidades de informação e atingir seus objetivos, a empresa precisa gerar um produto com as informações que respondam às demandas de seus usuários (os responsáveis por tomar decisões, por exemplo). Como a sua área/empresa seleciona as informações que lhe interessam, quais seus principais produtos (relatórios, apresentações, boletins etc) e quais os veículos de distribuição preferencial de sua informação? 
16) A inteligência Competitiva faz recomendações de acordo com as informações coletadas e selecionadas? Se sim, qual a relevância e estrutura dessas recomendações?

17) As atividades de inteligência Competitiva são reconhecidas em sua área? Você percebe incentivo e valorização dessas atividades, bem como de seus profissionais?

18) Existe um processo parametrizado de avaliação de desempenho da inteligência competitiva na empresa? Se sim, esse processo é auditado interna ou independentemente?

19) Você identifica a sua empresa como uma organização voltada a inovação em seu mercado? A inteligência competitiva suporta e fomenta esse processo?

20) A sua empresa possui um programa de Gestão do Conhecimento? Como ele funciona? Em sua área/empresa, existe uma relação entre as atividades de inteligência Competitiva e a Gestão do Conhecimento? 